\title{
Satisfação profissional e perfil de egressos em fisioterapia
}

\author{
Job satisfaction and profile of graduates in physical therapy
}

\author{
Danielle Chagas Pereira da Silval; Carlos Roberto Grazziano²; Andréa Corrêa Carrascosa ${ }^{2}$ \\ 1 Programa de Pós-graduação de Fisioterapia - Universidade Federal de São Carlos - UFSCar. São Carlos, SP - Brasil. \\ 2 Departamento de Ciências Biológicas e da Saúde - Universidade de Araraquara - UNIARA. Araraquara, SP - Brasil. \\ Endereço de Correspondência \\ Andréa Corrêa Carrascosa \\ Rua Carlos Gomes 1338, Centro. \\ 14.801-340 - Araraquara - SP, Brasil. \\ acarrascosa@uniara.com.br
}

\begin{abstract}
Resumo
Introdução: A percepção dos egressos sobre sua situação e satisfação profissional é fundamental para identificar a relação entre a formação profissional e as exigências do mercado de trabalho. Objetivo: Caracterizar o perfil de egressos em fisioterapia e analisar fatores associados com satisfação e formação profissional. Métodos: Foram convidados egressos formados entre 2001 e 2013. Utilizou-se questionário online com questões sobre caracterização do egresso, aprimoramento profissional, mercado de trabalho e satisfação profissional. Resultados: Participaram 149 egressos, 50,5\% solteiros e 75,8\% mulheres. A qualificação profissional foi verificada em $82,6 \%$. Ingressaram no mercado de trabalho em menos de 1 ano $69,8 \%$. Atuavam com fisioterapia $85,9 \%$. A principal área de atuação foi traumatologia e ortopedia $(58,4 \%)$. Satisfação profissional foi relatada por $71,8 \%$ e satisfação econômica por 17,4\%. Conclusão: A maioria dos egressos atuava em fisioterapia e buscou qualificação profissional. Grande parte dos participantes encontrava-se satisfeita profissionalmente, mas insatisfeita economicamente.
\end{abstract}

Descritores: Fisioterapia; Satisfação no trabalho; Percepção.

\begin{abstract}
Introduction: Graduates' perception about their situation and professional satisfaction, which are fundamental to identify the relation between a professional formation and some demands of job market. Objective: To describe the characteristics of physical therapy graduates' profiles and to analyze factors associated with satisfaction and professional training. Methods: It was invited graduates from 2001 to 2013. An online questionnaire about the characterization of graduates, professional improvement, job market and professional satisfaction was used. Results: There were 149 graduates, singles (50.5\%) and women (75.8\%). About $82.6 \%$ were verified professional qualification. In less than one year $69.8 \%$ entered the labour market and $85.9 \%$ worked with physiotherapy. The main areas of practice were traumatology and orthopedics (58.4\%). Professional satisfaction was reported by $71.8 \%$ people and economic satisfaction only by $17.4 \%$. Conclusion: The majority of the graduates worked in physiotherapy and sought professional qualification. Most of them were professionally satisfied but economically insatisfied.
\end{abstract}

Keywords: Physical therapy specialty; Job satisfaction; Perception. 


\section{Introdução}

A história da fisioterapia, desde o reconhecimento legal da profissão no Brasil pela lei ${ }^{\circ}$ 938 de $1969^{1}$ apresentou diferentes etapas, cada qual com sua peculiaridade e importância para o contexto atual.

O papel do fisioterapeuta evoluiu de uma atuação sem autonomia e subordinada aos médicos para um profissional liberal, inserido em uma ampla área de atuação e com diversas atividades profissionais, como direção de serviços, assessoria técnica, exercício do magistério, supervisão de profissionais e alunos, dentre outras ${ }^{2}$.

A diversidade das áreas de atuação fisioterapêutica e o elevado número de profissionais formados determinou uma crescente concorrência no mercado de trabalho. Neste contexto, as características da Instituição de Ensino Superior - IES, como o seu histórico e tradição, seu reconhecimento pelo Ministério da Educação (MEC), infraestrutura, disciplinas ofertadas, estágios e metodologias de avaliação devem ser aspectos avaliados, pois são determinantes da sua qualidade e importantes para a formação de profissionais reflexivos, competentes e aptos para a atuação profissional ${ }^{3-6}$.

A avaliação periódica das Instituições de Ensino Superior é realizada pelo MEC e busca identificar se há equilíbrio entre as competências profissionais adquiridas durante a graduação e as exigências do mercado de trabalho ${ }^{4}$. Os resultados destas avaliações dão subsídios para a readequação das estruturas curriculares diante das novas realidades sociais e diferentes necessidades de atuação profissional.

Com o objetivo de ampliação da avaliação educacional, o Ministério da Educação implantou em 2004, o Sistema Nacional de Avaliação da Educação Superior (SINAES) $)^{7,8}$ permitindo, além de uma visão global das Instituições de Ensino Superior (IES), a verificação das próprias instituições sobre sua qualidade e responsabilidade social ${ }^{9,10}$.

Uma das dimensões proposta pelo SINAES para a avaliação dos cursos de graduação é a avaliação sob a percepção dos egressos, na qual são coletadas informações sobre a inserção profissional, sobre a situação atual, o índice de ocupação entre eles e a relação entre a ocupação e a formação profissional ${ }^{11,12}$.

Uma vez que essa avaliação utiliza a visão de egressos, devem-se também considerar uma variedade de fatores que contribuem para a sua satisfação pessoal e profissional ${ }^{5,13}$. Para Câmara e Santos ${ }^{12}$, o conceito de satisfação deve ser avaliado em termos de expectativa e de percepção dos sujeitos, e assim, deve ser obtido por meio de questionamentos diretamente aos profissionais.

Apesar da percepção dos egressos com relação à profissão ser um aspecto obrigatório para o processo de avaliação institucional e fundamental para a adequação das propostas curriculares ${ }^{14}$, estas informações são pouco abordadas na literatura como indicadores das avaliações institucionais ${ }^{4,10}$.

Este estudo foi realizado com o objetivo de caracterizar o perfil dos egressos do curso de graduação em fisioterapia da Universidade de Araraquara-UNIARA e analisar a prevalência e fatores associados à satisfação com a formação profissional.

\section{Materiais e método}

Esta pesquisa foi aprovada pelo Comitê de Ética em Pesquisa da UNIARA (CAAE: 27942214.5.0000.5383).

A população de estudo foi de egressos graduados em fisioterapia pela Universidade de Araraquara, entre 2001 e 2013 ( $n=685)$. No entanto, somente $453(66,13 \%)$ puderam ser contatados por via eletrônica.

Foi utilizado para a coleta das informações um questionário padronizado elaborado especificamente para esta pesquisa. Este instrumento era composto de questões fechadas e abertas, construídas com base nos núcleos de informações sobre egressos propostos no manual do Sistema Nacional de Avaliação da Educação Superior (SINAES) para auto avaliação institucional ${ }^{11}$. 
O questionário era composto de 21 questões, divididas em 4 temas: Caracterização do egresso (questões de 1 a 8); Aprimoramento profissional (questões de 9 a 11); Mercado de Trabalho (questões de 12 a 17); Satisfação com a profissão (questões de 18 a 21).

Para a localização do contato dos egressos foi realizada busca pelos e-mails e telefones nos arquivos da Coordenação de Curso e Secretaria Acadêmica da Universidade, além de consulta aos sites de relacionamento e comunidades de fisioterapia. Foi criado um banco de cadastro com o nome e correio eletrônico dos egressos.

O envio do link para preenchimento do questionário foi realizado uma única vez para todos os e-mails válidos. Também foi enviada uma carta convite com orientações sobre o preenchimento do questionário juntamente com o Termo de Consentimento Livre e Esclarecido (TCLE).

O banco de dados foi construído utilizando o Programa SPSS (Statistical Package For The Social Science versão 11.5 para Windows). A análise descritiva dos dados foi realizada por meio do cálculo das frequências, média, desvio padrão e valores mínimos e máximos.

\section{Resultados}

Do total de egressos convidados para participar $(\mathrm{n}=453)$, apenas 149 (32,9\%) aceitaram e foram incluídos neste estudo. A figura 1 apresenta as etapas de seleção e inclusão da amostra.

O número de participantes, por turma, variou de 6 a $24(2,2 \%$ a $8,8 \%$ do total da amostra), sendo que nenhuma turma ficou sem representação no estudo.

Fonte: Próprio autor
A idade média dos participantes foi de $29,63 \pm 4,34$ anos, com a mínima de 22 e a máxima de 48 anos.

A caracterização sociodemográfica da amostra encontra-se na tabela 1.

Observa-se que a maioria dos egressos era solteira (50,3\%), sem filhos $(79,9 \%)$ e do sexo feminino $(75,8 \%)$. Apesar de grande parte dos egressos continuarem residindo em Araraquara após a graduação $(43,6 \%)$, durante a realização do curso essa quantidade era superior $(57,7 \%)$.

A caracterização dos participantes segundo os aspectos relacionados com o aprimoramento profissional está apresentada na tabela 2 .

Verifica-se que somente $17,4 \%$ dos egressos não apresentaram continuidade na formação após a graduação e a maioria realizou especialização ou aprimoramento (64,5\%). Em relação à participação em eventos científicos, $84,6 \%$ relataram participar.

Dentre as causas apontadas com maior frequência pelos egressos para a dificuldade em participar de eventos científicos estavam o 'alto

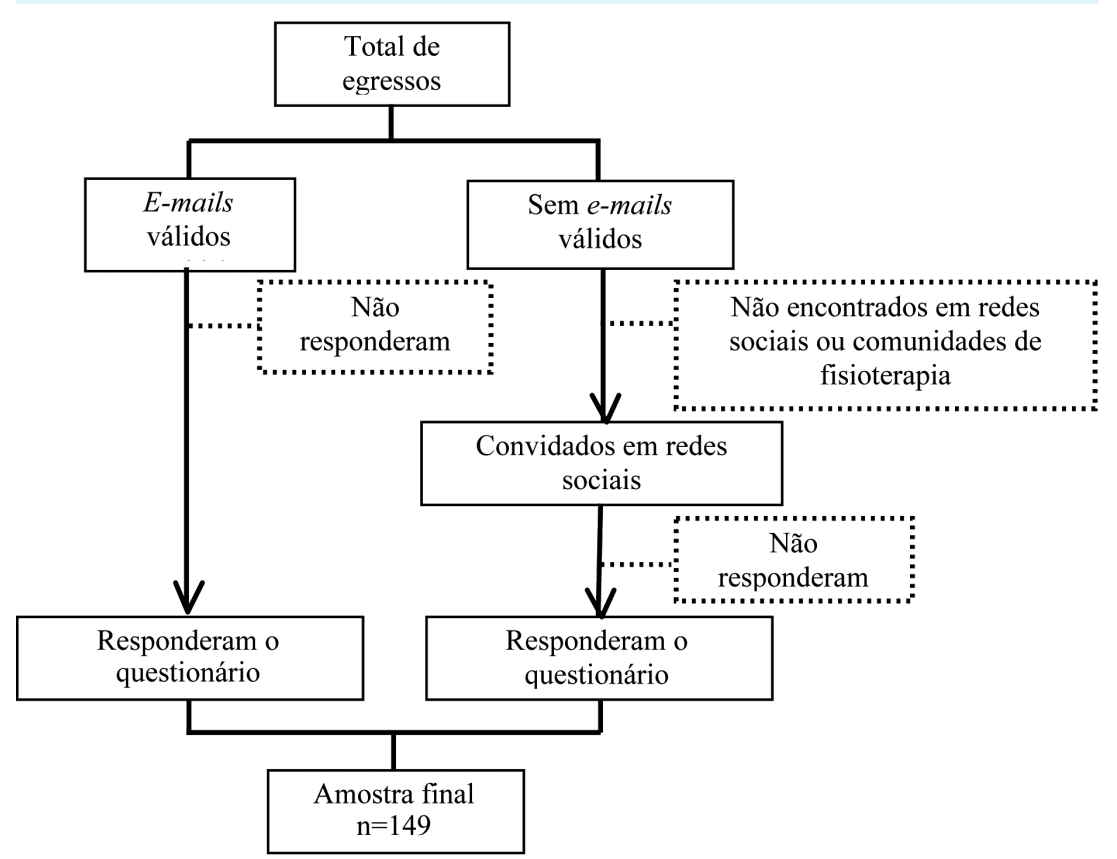

Figura 1: Fluxograma das etapas de seleção e inclusão da amostra. Araraquara, 2016 
Tabela 1: Caracterização dos egressos de fisioterapia da Universidade de Araraquara ( $\mathrm{n}=149)$. Araraquara, 2016

\begin{tabular}{|c|c|c|}
\hline Características & $\mathrm{N}$ & $\%$ \\
\hline \multicolumn{3}{|l|}{ Sexo } \\
\hline Feminino & 113 & 75,8 \\
\hline Masculino & 36 & 24,2 \\
\hline \multicolumn{3}{|l|}{ Estado civil } \\
\hline Casado & 66 & 44,3 \\
\hline Divorciado & 6 & 4,1 \\
\hline Solteiro & 75 & 50,3 \\
\hline Viúvo & 2 & 1,3 \\
\hline \multicolumn{3}{|l|}{ Quantidade de filhos } \\
\hline 0 & 119 & 79,9 \\
\hline 1 & 24 & 16,1 \\
\hline 2 & 6 & 4,0 \\
\hline \multicolumn{3}{|c|}{ Residência durante graduação } \\
\hline Araraquara & 86 & 57,7 \\
\hline Região de Araraquara* & 31 & 20,8 \\
\hline Outras localidades & 32 & 21,5 \\
\hline \multicolumn{3}{|l|}{ Residência após a graduação } \\
\hline Araraquara & 65 & 43,6 \\
\hline Região de Araraquara* & 39 & 26,2 \\
\hline Outras localidades & 45 & 30,2 \\
\hline \multicolumn{3}{|l|}{ Faixas salariais } \\
\hline Até 2 SM & 42 & 28,2 \\
\hline De 2 a 5 SM & 76 & 51,0 \\
\hline Acima de 5 SM & 31 & 20,8 \\
\hline Total & 149 & 100,0 \\
\hline
\end{tabular}

custo destes eventos científicos' $(65,1 \%)$, seguido pela 'falta de tempo' (51,7\%).

As informações sobre a inserção dos egressos fisioterapeutas no mercado de trabalho encontram-se na Tabela 3.

A maioria dos participantes $(69,8 \%)$ ingressou no mercado de trabalho em menos de 1 ano pós-formado. Quando questionados sobre a atuação em fisioterapia, 21 (14,1\%) responderam atualmente não trabalhar na área de formação e $128(85,9 \%)$ disseram que atuam como fisioterapeutas, dentre os quais $53,7 \%$ são profissionais liberais (autônomos) e 16,1\% trabalham em clínicas e hospitais.
Tabela 2: Nível de qualificação e participação em eventos científicos dos egressos de fisioterapia da Universidade de Araraquara $(\mathrm{n}=149)$. Araraquara, 2016

\begin{tabular}{|c|c|c|}
\hline & $\mathrm{n}$ & $\%$ \\
\hline \multicolumn{3}{|l|}{ Níveis de qualificação } \\
\hline Graduação & 26 & 17,4 \\
\hline Especialização & 84 & 56,4 \\
\hline Aprimoramento & 12 & 8,1 \\
\hline Mestrado & 16 & 10,7 \\
\hline Doutorado & 9 & 6,0 \\
\hline Pós-doutorado & 2 & 1,3 \\
\hline \multicolumn{3}{|c|}{ Participação em eventos científicos } \\
\hline Sim, de forma satisfatória & 50 & 33,6 \\
\hline $\begin{array}{c}\text { Sim, mas não com a frequência } \\
\text { que gostaria }\end{array}$ & 76 & 51,0 \\
\hline Não & 23 & 15,4 \\
\hline Total & 149 & 100,0 \\
\hline
\end{tabular}

A avaliação dos aspectos relacionados com a satisfação profissional dos egressos está apresentada na Tabela 4.

Observa-se que a maioria dos egressos $(71,8 \%)$ se apresentou satisfeita ou totalmente satisfeita com a profissão. No entanto, grande parte $(42,3 \%)$ apresentou-se insatisfeita ou totalmente insatisfeita com o aspecto financeiro.

A maioria dos egressos considera-se profissionalmente bem-sucedida $(61,1 \%)$ e escolheria a fisioterapia novamente como profissão (63,1\%).

\section{Discussão}

O contato com egressos de uma Instituição de Ensino Superior e o levantamento de informações sobre sua situação profissional é determinante para a avaliação da qualidade de ensino desta instituição e a constante readequação das estruturas curriculares de acordo com as necessidades do mercado de trabalho.

A utilização de questionários online para a coleta de informações aumenta o acesso dos voluntários à pesquisa e reduz os seus custos ${ }^{3,5,12,14}$. A adesão neste estudo foi de 32,9\% dentre os convidados. Esta participação é superior à rela- 
Tabela 3: Inserção dos egressos de fisioterapia da Universidade de Araraquara ( $\mathrm{n}=149)$, no mercado de trabalho.

Araraquara, 2016

\begin{tabular}{ccc}
\hline & $\mathrm{n}$ & $\%$ \\
\hline Função/cargo $^{\#}$ & & \\
Desempregado & 11 & 7,4 \\
Nenhuma função da fisioterapia & 10 & 6,7 \\
Profissional liberal & 80 & 53,7 \\
Funcionário (clínica, hospital) & 24 & 16,1 \\
Acadêmica & 14 & 9,4 \\
Servidor público & 10 & 6,7 \\
Gerência & 9 & 6,0 \\
\hline Área de atuação da fisioterapia\# & & \\
Desempregado & 11 & 7,4 \\
Nenhuma área da fisioterapia & 10 & 6,7 \\
Traumatologia e ortopedia & 87 & 58,4 \\
Neurologia & 69 & 46,3 \\
Geriatria & 42 & 28,2 \\
Saúde da mulher & 36 & 24,2 \\
Cardiorrespiratória & 24 & 16,1 \\
Reumatologia & 18 & 12,1 \\
Saúde do trabalhador & 15 & 10,1 \\
Outras áreas da fisioterapia & 24 & 16,1 \\
\hline
\end{tabular}

Tempo decorrido para o ingresso no mercado de trabalho

\begin{tabular}{|c|c|c|}
\hline Não ingressou no mercado de trabalho & 10 & 6,7 \\
\hline Menos de 1 ano & 104 & 69,8 \\
\hline De 1 a 3 anos & 29 & 19,5 \\
\hline De 3 a 4 anos & 2 & 1,3 \\
\hline Mais de 4 anos & 4 & 2,7 \\
\hline Total & 149 & 100 \\
\hline
\end{tabular}

\# O valor absoluto total supera 149 e o valor percentual somado ultrapassa $100 \%$ porque cada egresso podia indicar mais de uma resposta.

Fonte: Próprio autor. tada por Câmara e Santos ${ }^{12}(15,7 \%)$ e inferior à encontrada por Freitas e Lopes ${ }^{15}(66,4 \%)$.

Alguns fatores que podem estar relacionados com a baixa participação de egressos em pesquisas são a migração destes para locais distantes da IES após a formatura - característica desta pesquisa, na qual 14,1\% dos egressos deixaram a cidade em que realizaram a graduação - e o tempo decorrido entre a avaliação e o ano de conclusão que segundo Sancha ${ }^{3}$ pode reduzir o comprometimento dos ex-alunos com a pesquisa.

Explicada pelo relevante contexto histórico no processo de construção da fisioterapia, a predominância feminina entre os profissionais desta área sempre esteve em evidência ${ }^{16}$ e atualmente ainda é acentuada, sendo evidenciada neste estudo pela presença de 75,8\% de mulheres na amostra. Câmara e Santos ${ }^{12}$, Sancha ${ }^{3}$, Pinheiro et al. ${ }^{17}$ e Czapieyski e Sumiya ${ }^{18}$ também apontaram a prevalência de indivíduos do sexo feminino $(75 \%$, $74,5 \%, 91 \%$ e $81,0 \%$ respectivamente) dentre os profissionais fisioterapeutas, confirmando esta característica entre os profissionais da área.

Pesquisas ${ }^{12,19}$ com egressos têm apontado divergência quando discutida a renda mensal de fisioterapeutas que foi registrada entre 2 e 5 salários-mínimos (SM) por Thomas et al..$^{19}$ e de 2,8 a mais de $20 \mathrm{SM}$ por Câmara e Santos ${ }^{12}$. A faixa salarial apontada por $51 \%$ dos participantes deste estudo foi de 2 a $5 \mathrm{SM}$. A comparação com os outros estudos, no entanto, deve ser realizada com cuidado, levando em conta as diferenças econômicas e sociais de cada momento da história.

Tabela 4: Respostas dos egressos em fisioterapia ( $\mathrm{n}=149)$ para os aspectos relacionados com a satisfação profissional. Araraquara, 2016

\begin{tabular}{cccccc}
\hline & \multicolumn{5}{c}{ Respostas n (\%) } \\
\cline { 2 - 6 } & $\begin{array}{c}\text { Totalmente } \\
\text { insatisfeito }\end{array}$ & Insatisfeito & Neutro & Satisfeito & $\begin{array}{c}\text { Totalmente } \\
\text { satisfeito }\end{array}$ \\
\hline Satisfação com a profissão & $4(2,7)$ & $5(3,4)$ & $33(22,1)$ & $62(41,6)$ & $45(30,2)$ \\
Satisfação financeira com a profissão & $22(14,8)$ & $41(27,5)$ & $60(40,3)$ & $23(15,4)$ & $3(2,0)$ \\
\hline & $\begin{array}{c}\text { Com certeza } \\
\text { não }\end{array}$ & Não & Indiferente & Sim & $\begin{array}{c}\text { Com certeza } \\
\text { sim }\end{array}$ \\
$\begin{array}{c}\text { Considera-se um profissional } \\
\text { bem-sucedido? }\end{array}$ & $12(8,1)$ & $14(9,4)$ & $32(21,5)$ & $43(28,9)$ & $48(32,2)$ \\
Escolheria a mesma profissão? & $20(13,4)$ & $13(8,7)$ & $22(14,8)$ & $25(16,8)$ & $69(46,3)$ \\
\hline
\end{tabular}

Fonte: Próprio autor. 
Buscando ascensão profissional e econômica, grande parte dos profissionais opta pela continuidade dos estudos e qualificação profissional após a graduação, assim, dentre os egressos avaliados, $82,6 \%$ relataram ter realizado algum tipo de especialização ou aprimoramento. Câmara e Santos ${ }^{12}$ e Mair et al. ${ }^{20}$ também apontaram, respectivamente, que $75,0 \%$ e $78,4 \%$ dos egressos avaliados continuaram seus estudos depois de formado.

A autonomia na profissão é considerada um atraente significativo devido a benefícios como a possibilidade de gerenciar as relações de trabalho, manter horários mais flexíveis e, em muitos casos, salários maiores ${ }^{16}$. Apesar de Câmara e Santos ${ }^{12}$ sugerirem que este exercício liberal da profissão esteja em declínio, neste estudo 53,7\% dos participantes relatou atuar como profissional liberal, superando a atuação em clínicas e hospitais (16,1\%), área acadêmica $(9,4 \%)$ e serviços púbicos $(6,7 \%)$.

Assim como há grande variedade de locais de trabalho, áreas de atuação diversificadas também estão disponíveis para estes profissionais. Na história da fisioterapia a atuação na área de traumatologia e ortopedia sempre se configurou como a mais frequente, caracterizada, principalmente, pela reabilitação de fraturas e outras lesões do sistema musculoesquelético ${ }^{16}$. Esta área de atuação predominou também entre os egressos avaliados neste estudo $(58,4 \%)$ o que, segundo Câmara e Santos ${ }^{12}$, consolidou-se pela vasta quantidade de cursos de especialização direcionados para este campo.

O reconhecimento da profissão e o crescimento da demanda por profissionais fisioterapeutas em serviços de saúde podem ser observados pela rápida inserção dos egressos no mercado de trabalho ${ }^{19}$. A maioria dos participantes $(69,8 \%)$ relatou o início da atuação profissional em menos de 1 ano após a conclusão da graduação, e somente $6,7 \%$ não chegaram a ingressar no mercado de trabalho. Freitas e Lopes ${ }^{15}$ também encontraram resultados positivos sobre a inserção profissional, apontando que 75,5\% dos 53 egressos avaliados em seu estudo estavam empregados na profissão em menos de 1 mês após a formatura e apenas $1,9 \%$ ainda se encontravam desempregados ao fim de 1 ano de formado.

A rápida inserção no mercado de trabalho, assim como aspectos psicossociais ${ }^{5,13}$ e outra diversidade de fatores intrínsecos e extrínsecos podem ser determinantes de satisfação no trabalho.

Satisfação profissional foi relatada por 85,8\% dos egressos no estudo de Câmara e Santos $^{12}$, 86,3\% por Freitas e Lopes ${ }^{15}$ e 93,2\% por Sancha ${ }^{3}$. Estes dados são próximos aos encontrados neste estudo, no qual $71,8 \%$ declararam estar satisfeitos profissionalmente.

Quando a satisfação econômica foi questionada, apenas 17,4\% declararam-se satisfeitos. Leirós-Rodríguez ${ }^{21}$ aponta falhas na formação profissional dos fisioterapeutas como a incapacidade de gestão das informações além de dificuldades na resolução de problemas e na tomada de decisões. Estas limitações podem, entre outros aspectos, serem fatores contribuintes para a desvalorização profissional e redução da remuneração, em um momento que o mercado de trabalho apresenta-se competitivo e busca por profissionais com amplas competências e habilidades.

Espera-se que esta pesquisa tenha colaborado para o conhecimento do perfil de egressos em fisioterapia e dos aspectos relacionados com a sua satisfação profissional. Entretanto, é válido ressaltar a carência de estudos científicos com egressos de fisioterapia que possibilitem comparações e mais discussões a respeito. Assim, sugere-se a ampliação desse tema em pesquisas posteriores com o objetivo de facilitar seu entendimento e possibilitar intervenções apropriadas a partir destas informações.

\section{Conclusão}

Concluiu-se que a maioria dos egressos apresentou rápida inserção no mercado de trabalho, atuava em fisioterapia e buscou qualificação profissional. Grande parte dos participantes encontrava-se satisfeita profissionalmente, mas insatisfeita economicamente. 


\section{Agradecimentos}

Agradecemos a participação dos egressos em fisioterapia da Universidade de Araraquara UNIARA e a bolsa de iniciação científica PIBIC/ CNPq/UNIARA.

\section{Referências}

1. Brasil. Lei no 938 , de 14 de outubro de 1969. Regulamentação da Profissão de Fisioterapeuta e Terapeuta Ocupacional. Diário Oficial da União, Brasília, n 197, 14 out. 1969. Seção 1. pág. 3.658.

2. Utida VHS, Paganini J, Fagundes RR, Amaral LHR, Oliveira VRC. Estrutura Curricular dos Cursos de Fisioterapia do Estado de Goiás: um destaque a saúde coletiva. Revista Movimenta. 2012;5(4):293-302.

3. Sancha CCM. A trajetória dos egressos do Programa de Aprimoramento Profissional: quem são e onde estão os enfermeiros, fisioterapeutas e psicólogos dos anos de 1997 e 2002 [Dissertação]. Universidade de São Paulo, Faculdade de Saúde Pública; 2008.

4. Lousada ACZ, Martins GA. Egressos como fonte de informação à gestão dos cursos de ciências contábeis. Rev. Cont. Finanç. 2005; 16(37):73-84.

5. Branquinho NCSS. Satisfação dos egressos do curso de graduação em enfermagem de uma universidade pública. [Dissertação]. Universidade Federal de Goiás, Faculdade de Enfermagem; 2012. 108 f.

6. Colenci R, Berti HW. Formação profissional e inserção no mercado de trabalho: percepções de egressos de graduação em enfermagem. Rev. Esc. Enferm. USP. 2012;46(1):158-66.

7. Brasil. Lei $\mathrm{n}^{\circ} 10.861$, de 14 de abril de 2004. Institui o Sistema Nacional de Avaliação da Educação Superior - SINAES e dá outras Providências. Diário Oficial da República Federativa do Brasil, Brasília, 15 abr. 2004. Seção 1. p. 3-4.

8. Brasil. Portaria n ${ }^{\circ}$ 2.051, de 9 de julho de 2004. Regulamenta os procedimentos de avaliação do Sistema Nacional de Avaliação da Educação Superior (SINAES), instituído na lei no 10.861, de 14 de abril de 2004. Diário Oficial da República Federativa do Brasil, Brasília, 12 jul. 2004. Seção 1.

9. Souza NVDO, Correira LM, Cunha LS, Eccard J, Patrício RA, Antunes TCS, et al. O egresso de enfermagem da FENF/UERJ no mundo do trabalho. Rev. Esc. Enferm. USP. 2011;45(1):250-7.
10. Meira MDD, Kurcgant P. Avaliação de curso de graduação segundo egressos. Rev. Esc. Enferm. USP (online). 2009; 43(2):481-5.

11. Brasil. Ministério da Educação. Comissão Nacional de avaliação do Ensino Superior (CONAES). Orientações Gerais para o Roteiro de Auto-Avaliação das Instituições. Brasília, 2004.

12. Câmara AMCS, Santos LLCP. Um Estudo com Egressos do Curso de Fisioterapia da Universidade Federal de Minas Gerais (UFMG) - 1982-2005. Rev. bras. educ. méd. 2012;36(1,Supl.1):5-17.

13. Marqueze EC, Moreno CRC. Satisfação no trabalho: uma breve revisão. Rev. bras. saúde ocup. 2005;30(112):69-79.

14. Cambiriba TDC, Ferronato AF, Fontes KB. Percepções de egressos de enfermagem frente a inserção no mercado de trabalho. Arq. ciências saúde UNIPAR. 2014; 18(1):27-32.

15. Freitas S, Lopes AMF. O Primeiro Emprego dos Licenciados em Fisioterapia pela ESSA. Re(habilitar) - Revista da ESSA. 2005;1:49-75.

16. Oliveira VRC. Reconstruindo a história da fisioterapia no mundo. Revista Estudos. 2005;32(4):509-534.

17. Pinheiro LBC, Diógenes PN, Figueiras MC, Abdon APV, Lopes EAB. Conhecimento de graduandos em Fisioterapia na Universidade de Fortaleza sobre o Sistema Único de Saúde. Fisioter. Pesqui. 2009;16(3):211-6.

18. Czapieyski FN, Sumiya A. Assessment of the degree of satisfaction of physical therapy students with the academic experience. Fisioter. Mov. 2014;27(1):119-25.

19. Thomas DR, Soares MF, Braun DS. Perfil dos egressos do curso de fisioterapia do Instituto Cenecista de Ensino Superior de Santo Ângelo. Revista Saúde Integrada. 2013; 6:309-25.

20. 20. Mair V, Yoshumori DY, Cipriano GJ, Castro SS, Avino R, Buffoo E et al. Perfil da fisioterapia na reabilitação cardiovascular no Brasil. Fisioter. Pesqui. 2008; 15(4):333-8.

21. 21. Leirós-Rodríguez R, Souto-Gestal AJ, GarcíaSoidán JL. Post-graduate education requirements for access to jobs in physical therapy. Educación Médica. 2017;1-6. 